This manuscript version is made available under the CC-BY-NC-ND 4.0

license http://creativecommons.org/licenses/by-nc-nd/4.0/

\title{
Development of a sweating thermal skin simulant for heat transfer evaluation of clothed human body under radiant heat hazard
}

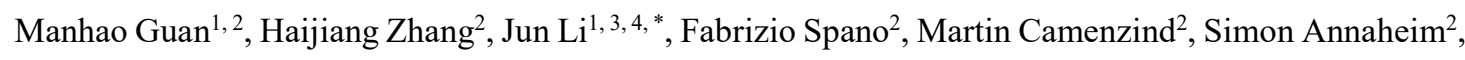
René Michel Rossi ${ }^{2, *}$

${ }^{1}$ College of Fashion and Design, Donghua University, 200051, Shanghai, China

${ }^{2}$ Empa, Swiss Federal Laboratories for Materials Science and Technology, Laboratory for Biomimetic Membranes and Textiles, CH-9014, St. Gallen, Switzerland

${ }^{3}$ Key Laboratory of Clothing Design and Technology, Donghua University, Ministry of Education, 200051, Shanghai, China

${ }^{4}$ Tongji University Shanghai Institute of Design and Innovation, Shanghai 200092, China

"Correspondence and requests for materials should be addressed to R.R. (email: rene.rossi@empa.ch) or J.L. (email: lijun@dhu.edu.cn)

\begin{abstract}
:
Human perspiration highly affects body heat dissipation as well as heat and mass transfer in clothing systems. Nevertheless, current skin simulant systems for assessing heat transfer under high heat exposure simply simulate the dry skin state. This fact limits the validity of such systems as perspiration and mass transfer exist during high heat exposure conditions. In this study, an active sweating skin simulant was developed using the polydimethylsiloxane material and with controllable sweat rates for heat transfer assessment under radiant heat hazards, considering mass transfer as well. In the dry state, the temperature and its variation rate of the skin simulant with water-filled sweating channels show good agreement with the ISO standard numerical model. For sweating conditions, the results showed that the wet conduction facilitated heat transfer towards the skin by $5-8 \%$ at the beginning of sweating. With continuous sweat release, the surface temperature rise was attenuated due to the additional heat capacity induced by additional moisture in the clothing system. The low standard deviations, below $2^{\circ} \mathrm{C}$, and coefficients of variation, below $10 \%$, for the temperature measurements under various sweat rates, indicated good reproducibility. This research provides the first to consider active sweating in skin simulant systems under high heat exposures. This approach provides new insights into heat transfer in protective clothinghuman skin systems under extreme heat exposure, contributing to realistically evaluating the thermal protective performance of clothing materials under sweating conditions.
\end{abstract}

\section{Keywords:}

Active sweating; thermal skin simulant; moisture effect; thermal behaviors; radiant heat.

\section{Introduction}

Human-centred thermal systems, e.g., heating, ventilation and air-conditioning (HVAC) systems [1, 2], phase change materials (PCMs) [3, 4] and thermal protection systems [5-7] are common technologies to improve thermal comfort and/or avoid heat injuries to the human body. In the design and research of these technologies, the manikin test is one of the main methods to examine new concepts, optimize design parameters, and assess system performance [8]. The manikin can be used to quantify energy transfer 
performance, and thus, to assess the effectiveness of these systems in improving human thermal performance.

Currently, there are two kinds of manikins used for the energy transfer assessment. One category is thermal manikins that simulate the constant skin temperature and constant power (metabolic) output of the human body. This kind of manikin can be used to evaluate the system performance in maintaining the body's thermal balance and improving thermal comfort. Itani et al. used a thermal manikin to measure the thermal resistance of a PCM cooling vest [9] and predict the local torso skin temperature [10]. Shim et al. [11] measured the heat loss of one- and two-layer PCM bodysuits from a thermal manikin as it was moved from a warm chamber to a cold chamber and back again. Yoo et al. [12] evaluated the heating and cooling effects of four-layer PCM garments by measuring temperature changes in the air layers of the microclimate within clothing using a human-clothing-environment simulator. By using a skinclothing-environment system, Haghighat et al. [3] predicted the thermoregulating performance of the core-shell fibrous layers containing PCM under body conditions. A numerical thermal manikin was used to evaluate the airflow in the compartment to assess human thermal comfort under an HVAC system [1]. These types of physical manikins can simulate the dry and sweating state of the human body while the numerical simulation of thermal manikins currently only simulates the dry state of the human body [13]. When simulating the sweating state, pre-wetted fabric is generally used to achieve a saturated moisture surface. Therefore, gaseous sweat is the research focus, without precise control over the liquid sweat. The influence mechanism of liquid sweat in heat transfer thus cannot be assessed.

The other category is flame/radiation manikins, which can be used to assess the system performance in preventing skin burns under high heat exposure. Various thermal sensors have been developed to evaluate heat transfer through the skin [14]. The general approach is to use the thermal sensor to assess the incident heat flux on the skin surface; the heat flux is further taken as the data input of a numerical model for temperature computation at different skin depths and burn injury prediction [15]. The development of thermal sensors only simulates the dry state of human skin by using copper disk, thermoset polymer or colorceron [16-21]. Most numerical models simulating heat transfer through skin also only consider the dry heat transfer. In standard evaluation methods (i.e., ASTM F1930 [22], ISO 13506-2 [15]), the thermal exposure is assumed as a transient one-dimensional heat diffusion problem in which the temperature within the epidermis and dermis layers of skin and subcutaneous tissue varies with both depth and time. The Pennes-bioheat equation [23], further considering blood perfusion and metabolic heat generation, is one commonly used model to simulate skin thermal behaviours. Some numerical models consider water diffusion and vaporisation in skin $[24,25]$. These models simulate the water vaporisation from the skin surface by considering a saturated moisture pressure. Further, the model validation was performed with experimental data from living skin which includes the effect of blood and tissue fluid shifts but does not include the effect of active liquid sweating [25]. In a previous study, researchers developed a multilayered dry skin simulant with polydimethylsiloxane (PDMS) to directly measure the temperatures at different skin depths [26].

In practice, especially in industrial sites and firefighting, individuals usually sweat profusely. Researchers [27] have pointed out that sweating and the concomitant moisture in clothing systems can significantly affect the heat transfer process. Since the effect of sweating on the heat transfer was usually investigated through pre-wetted material [27-34], the moisture in the material evaporates during the heat exposure, and the material gradually dries out. It is apparent that this approach does not consider the possible effects of sustained liquid sweating on heat transfer. 
Consequently, there is no clear conclusion about the effect of sweat moisture on heat transfer. Some studies [33-35] showed that the internal moisture can weaken heat transfer while other researchers [27, 36-38] demonstrated the opposite effect, by a percentage less than 3-9 \% [39-41]. The effect of moisture on heat transfer seemed to be influenced by the amount of moisture, when the amount of added moisture was at a comparatively low level (e.g., $15-20 \%$ [42] and 30-40\% [43] of the clothing weight), the moisture enhanced the heat transfer most. To understand the very complex moisture transfer mechanisms, realistic simulations of human sweating are needed [19, 34]. Some first attempts were made by using a thermal torso with active liquid sweating [44-46]. However, the heat and moisture transfer of the thermal torso and manikins involves non-planar clothing material and/or air gaps, which may make it difficult to understand the basic mechanisms of heat and moisture transfer in the clothing material. Furthermore, since the thermal torso and manikins do not simulate the thermal properties of skin, heat transfer within the skin cannot be replicated and investigated through these instruments.

Therefore, our study aimed to develop a flat active sweating skin simulant that can be used to evaluate heat transfer in the human skin-clothing-environment system, especially under high heat exposure, and to assess the effectiveness of human-centred systems under sweating conditions. We developed the sweating thermal skin simulant by integrating a previously developed multi-layered approach of a dry thermal skin simulant [26] and our newly designed active sweating system. We implemented sweat channels in the dry skin simulant, and, using a low-pressure pump system, we achieved control of various sweat rates. To validate the effectiveness of the skin simulant with water-filled sweat channels in measuring heat transfer, we compared the measured results from the developed skin simulant with computed results from numerical models. To investigate the feasibility of the newly developed sweating function, active sweating measurements under different sweat rates were performed with clothing material and the moisture effect of active sweating on heat transfer was compared with that of the prewetted research.

\section{Methods}

\subsection{Development of the skin simulant}

Figure 1 presents a schematic diagram of the sweating thermal skin simulant. The skin simulant was designed to simulate human skin with three layers (i.e. the epidermis, dermis, and subcutaneous tissue) by implementing three polydimethylsiloxane (PDMS) layers with corresponding thermal properties. The PDMS techniques for developing the three layers of skin simulant were applied as described in the literature [26]. The thermal properties of each layer and the corresponding properties used in the ISO 13506-2 numerical model [15] are presented in Table 1. As demonstrated in a previous study [26], the thermal diffusivity of PDMS layers, as the most important parameter in determining heat flow [14], was within the range of human skin. Three thermocouples (wire diameter: $0.125 \mathrm{~mm}$, CHAL-005, unsheathed fine gage, OMEGA Engineering, USA) were applied in the centre position at the interfaces of the skin simulant between the epidermis and dermis (thermocouple I), between the dermis and subcutaneous tissue (thermocouple II) and at the back of the subcutaneous tissue (thermocouple III), measuring the temperature of the two interfaces (denoted as Int1 and Int2, respectively) and the bottom (denoted as Bot3) of the skin simulant. Current surface temperature measurement techniques still have limitations since the sensor setup variables (e.g., sensor type, attachments, environmental conditions) can meaningfully influence the measured temperature [47]. Thus, the skin simulant surface temperature measurement was not considered in the current development stage. In addition, to obtain a similar 
emissivity as human skin (0.957-0.989) [26, 48-51], the skin simulant surface was painted with a thin layer of black paint with an emissivity of 0.95 .

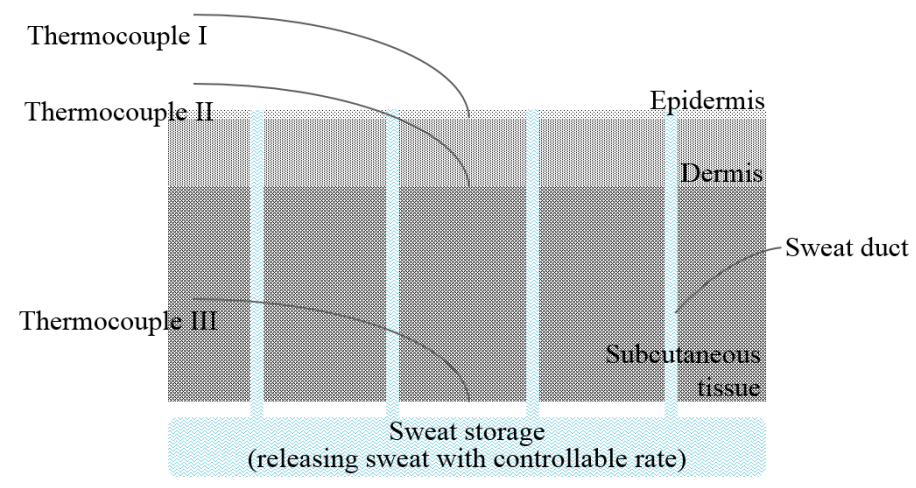

Fig. 1 Schematic diagram of the sweating thermal skin simulant

Table 1 Thermal properties of human skin used in ISO 13506-2:2017 and the developed skin simulant

\begin{tabular}{|c|c|c|c|c|c|c|c|c|}
\hline \multirow[b]{2}{*}{ Parameter } & \multirow[b]{2}{*}{ Unit } & \multicolumn{2}{|c|}{ Epidermis } & \multicolumn{2}{|c|}{ Dermis } & \multicolumn{2}{|c|}{ Subcutaneous Tissue } & \multirow[b]{2}{*}{ Water } \\
\hline & & $\begin{array}{l}\text { ISO } 13506- \\
2: 2017\end{array}$ & $\begin{array}{c}\text { Skin } \\
\text { simulant }\end{array}$ & $\begin{array}{c}\text { ISO } 13506- \\
2: 2017\end{array}$ & $\begin{array}{c}\text { Skin } \\
\text { simulant }\end{array}$ & $\begin{array}{l}\text { ISO } 13506- \\
2: 2017\end{array}$ & $\begin{array}{c}\text { Skin } \\
\text { simulant }\end{array}$ & \\
\hline Thickness & $10^{-6} \mathrm{~m}$ & 75 & 100.7 & 1125 & 1373.4 & 3885 & 3924.2 & -- \\
\hline $\begin{array}{l}\text { Thermal } \\
\text { conductivity }\end{array}$ & $\mathrm{W} / \mathrm{m} \cdot \mathrm{K}$ & 0.6280 & $0.23 \pm 0.03$ & 0.5820 & $0.23 \pm 0.03$ & 0.2930 & $0.13 \pm 0.00$ & 0.6130 \\
\hline $\begin{array}{c}\text { Volumetric heat } \\
\text { capacity }\end{array}$ & $\mathrm{J} / \mathrm{m}^{3} \cdot \mathrm{K}$ & $4.40 \mathrm{E}+06$ & $1.79 \mathrm{E}+06$ & $4.18 \mathrm{E}+06$ & $1.79 \mathrm{E}+06$ & $2.60 \mathrm{E}+06$ & $1.66 \mathrm{E}+06$ & $\begin{array}{c}4.20 \mathrm{E}+ \\
06\end{array}$ \\
\hline $\begin{array}{l}\text { Thermal } \\
\text { diffusivity }\end{array}$ & $\mathrm{m}^{2} / \mathrm{s} \times 10^{-7}$ & 1.43 & 1.29 & 1.39 & 1.29 & 1.13 & 0.78 & 1.46 \\
\hline
\end{tabular}

\section{Development of active sweating}

To simulate sweat glands, four sweating channels were drilled with needle tubes (inner diameter: 1.5 $\mathrm{mm}$ ) through the back to the surface of the skin simulant, to create four sweat nozzles. The relative position between the sweat nozzles and the thermocouples is shown in Fig. 2. A thermal guard isolation holder was developed for the skin simulant using calcium silicate to avoid heat loss from the sides and back of the skin simulant. Four channels were also drilled through the isolation holder for connecting the sweating channels with a low-pressure syringe pump system (neMESYS), which was used to control the sweat rate. Four syringes (volume: 6 mL, NORM-JECT Plastic Syringe, Restek Corporation, USA) were used as the water container for sweat release. The sweat rate of each sweat nozzle $\left(S R_{\text {skin simulant }}\right.$, $\mu \mathrm{L} / \mathrm{min}$ ) was the flow rate at which the syringe releases water and is calculated according to Eqn. (1).

$$
S R_{\text {skin simulant }}=\frac{S R_{\text {human body }} \times \frac{A_{\text {skin simulant }}}{A_{\text {human body }}}}{n}
$$

where $S R_{\text {human body }}$ is the assumed sweat rate of the whole human body, $\mu \mathrm{L} / \mathrm{min}, A_{\text {human body }}$ is the area of the whole human body, $\mathrm{m}^{2}, A_{\text {skin simulant }}$ is the area of the skin simulant, $\mathrm{m}^{2}$, and $n$ is the number of the sweat nozzles/channels. Based on the relationship between the local sweat rate and the whole-body sweat rate [52], we estimated the maximum local sweat rate to be $25.5 \mathrm{mg} /\left(\mathrm{cm}^{2} \cdot \mathrm{min}\right)$, corresponding to a $3 \mathrm{~L} / \mathrm{h}$ maximum whole-body sweat rate [27] (assuming a $1.8 \mathrm{~m}^{2}$ body surface area [53]). For each sweat nozzle, the corresponding sweat rate was $159.5 \mu \mathrm{L} / \mathrm{min}$. In this study, we applied 
four sweat rates 0, 30, 90 and $150 \mu \mathrm{L} / \mathrm{min}$, denoted as SR0, SR30, SR90 and SR150, for each nozzle. Sweat rate conversions between the human body and the skin simulant are shown in Table 2 .

To prepare the sweating system, we first filled each syringe with $6 \mathrm{~mL}$ distilled water and attached the syringes to the pump system. Then, the tips of the syringes and the corresponding sweat channels were connected using PTFE tubes and connectors. Before starting the system, the air in the entire sweating path was removed to ensure the target sweat rate.

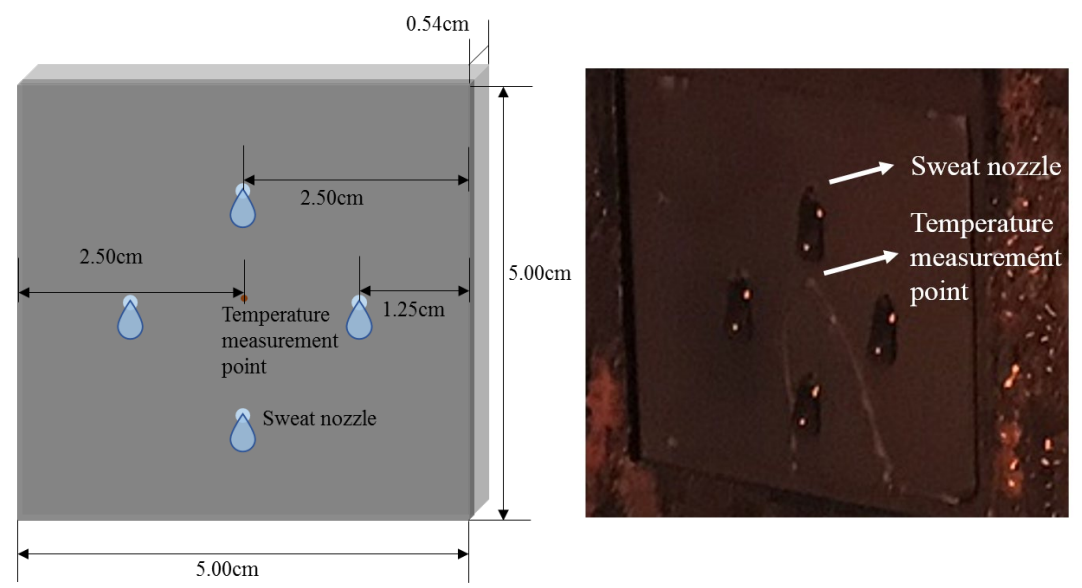

Fig. 2 Relative positions between the sweat nozzles and the temperature measurement point

Table 2 Sweat rate of the human body and the corresponding sweat rate/flow rate of the skin simulant

\begin{tabular}{cccccc}
\hline & \multicolumn{5}{c}{ Sweat rate/flow rate } \\
\hline Sweat rate of the human body $(\mathrm{g} / \mathrm{h})$ & 217.3 & 740.8 & 1787.7 & 2834.6 & 3000.0 \\
Local Sweat rate density $\left(\mathrm{mg} / \mathrm{min} \cdot \mathrm{cm}^{2}\right)$ & 0.0 & 4.8 & 14.4 & 24.0 & 25.5 \\
Sweat rate/Flow rate for the whole skin simulant $(\mathrm{L} / \mathrm{h})$ & 0.0 & 120.0 & 360.0 & 600.0 & 637.9 \\
Sweat rate/Flow rate for each sweat nozzle $(\mu \mathrm{L} / \mathrm{min})$ & 0.0 & 30.0 & 90.0 & 150.0 & 159.5 \\
\hline
\end{tabular}

The sweat rate conversion between the whole human body and local position comes from the literature [52].

\subsection{Validation of skin simulant}

For human skin with active liquid sweating under radiant heat, there is neither experimental temperature data available at different depths of human skin nor a corresponding theoretical model. There are some theoretical models describing water vaporization by considering the saturated vapour pressure on the epidermis. However, the theoretical model was validated by comparing with experimental data from living skin without mentioning the wet state. Besides, given the different wet states on the skin surface between the theoretical model (the saturated vapour pressure) and our skin simulant (various liquid sweat rates), there could be diverging results in the comparison and the comparability of the theoretical model with the skin simulant is limited. Therefore, validation of the skin simulant used for the evaluation of heat transfer within the human skin under the radiant heat exposure was done in two steps. First, the sweating skin simulant was validated in its dry state by comparing it with a standardized dry heat transfer numerical model according to ISO 13506-2 [15]. Second, an experiment with active sweating was conducted to validate the effect of sweating on heat transfer by comparing with previous pre-wetted experimental studies.

\subsubsection{Comparisons with a standardized numerical model}


For the validation of dry heat transfer, the temperatures at Int1, Int 2 and Bot 3 were compared with the corresponding temperatures of the numerical model ${ }^{1}$. By calculating the first derivative of the temperature versus the time, the variation rate of the temperature was also compared. A dry skin simulant constructed of the same PDMS layers has been already validated in a previous study [26]. Therefore, the validation purpose in this study was to assess the heat transfer of the new skin simulant with water-filled sweating channels. The skin simulant was exposed to different radiant heat intensities from 3.0 to 10.0 $\mathrm{kW} / \mathrm{m}^{2}$ (i.e. 3.0, 4.0, 5.0 and $10.0 \mathrm{~kW} / \mathrm{m}^{2}$, denoted as HF3, HF4, HF5 and HF10). The experimental setup was in accordance with ISO 6942:2002 [54]. An insulation panel was used as a shutter to start or stop radiant heat exposure. Before each test, the radiant heat intensity was calibrated with a thermal sensor (Schmidt-Boelter heat flux sensor, Medtherm Corporation, USA) to guarantee a maximum $0.05 \mathrm{~kW} / \mathrm{m}^{2}$ intensity variation. The experimental protocol consisted of three phases. In phase 1 , the shutter was kept closed for $20 \mathrm{~s}$. In phase 2 (heating phase), the shutter was open, and the skin simulant began to be exposed to the radiant heat for $40 \mathrm{~s}$. In phase 3 (cooling phase), the shutter was quickly closed again and the skin simulant exposure stopped for $60 \mathrm{~s}$. The temperatures of the skin simulant at Int1, Int 2 and Bot 3 were recorded at $10 \mathrm{~Hz}$. Before each test, the skin simulant was cooled to room temperature $\pm 2{ }^{\circ} \mathrm{C}$. Each test was repeated three times. For computing the numerical model, we applied two sets of skin parameters (i.e., thermal conductivity and volumetric heat capacity): (I) the original parameters in ISO 13506-2 (NM I) and (II) the same parameters as the skin simulant (NM II). The thicknesses of the skin layers used in NM I and NM II were the same as that used in the skin simulant.

Further, to identify the exact thermal properties that influenced the temperature difference between the skin simulant and NM I, we performed the numerical model computation with isometric change thermal properties. For the first group, we increased the thermal conductivity from the value of the skin simulant to that of NM I while keeping the volumetric heat capacity the same as the value of the skin simulant. The models were denoted as nm i(con), nm ii(con), nm iii(con) and $\mathrm{nm}$ iv(con), in turn. For the second group, we increased the volumetric heat capacity from the value of the skin simulant to that of NM I. The models were denoted as nm i(cap), nm ii(cap), nm iii(cap) and nm iv(cap), in turn. The results are provided in supplementary materials.

\subsubsection{Active sweating evaluation}

A similar experimental protocol was adopted as that described in section 2.2.1; however, the skin simulant started to release sweat in phase 2. To assess the effect of continuous sweating on the heat transfer and compare the moisture effect with pre-wetted material reported in previous research, the sweating experiment was performed with a clothing material. The textile sample was a common commercially-available thermal protective clothing material, denoted as TPC (fibre content: $34 \%$ aramid/ $33 \%$ lyocell/ 31\% modacrylic/ $2 \%$ anti-static fibre, weight: $241.6 \mathrm{~g} / \mathrm{m}^{2}$ [55], thickness: $0.6 \mathrm{~mm}$ [56], thermal resistance: $13.4 \times 10^{-3} \mathrm{~K} \cdot \mathrm{m}^{2} / \mathrm{W}$ [57], evaporative resistance: $2.7 \mathrm{~m}^{2} \cdot \mathrm{Pa} / \mathrm{W}$ [57]). Before testing, the thermal protective material was conditioned in a climatic chamber with $20.0 \pm 0.5^{\circ} \mathrm{C}$ air temperature and $65 \pm 2 \%$ relative humidity for at least 24 hours. Each test was repeated three times.

\section{Results and Discussion}

\subsection{Comparison of the skin simulant with the numerical models}

\footnotetext{
${ }^{1}$ Since the estimated area percentage between the thermocouple and the skin simulant is $0.25 \%$ and the results showed a very close temperature between the skin simulant and the numerical model, the effect of thermocouple on the heat transfer of the skin simulant could be neglected and the skin simulant could be compared with the numerical model with the same layer thickness.
} 
Figure 3 shows the temperature rise during and after the radiant heat exposure measured on the skin simulant and simulated by NM I and NM II. Figure 4 shows the corresponding temperature variation rate. As all radiant heat exposure scenarios (HF3, HF4, HF5 and HF10) showed similar temperature behaviours, the temperature behaviours under middle-level exposure, HF5, is used for the results presentation.

\subsubsection{Comparison with NM I}

\section{(1) Comparison of temperature rise}

Figure 3 (a) shows that for the radiant heat exposure HF5, the temperature rises at Int1 and Int 2 on the skin simulant were higher than the ones predicted by NM I (i.e., 20.9, $11.9^{\circ} \mathrm{C}$ higher). Based on the analyses of the numerical models (Fig. S1), the higher temperatures of the skin simulant could be due to the lower thermal conductivity and/or the lower volumetric heat capacity.

The temperature at Bot 3 on the skin simulant started to increase at the later stages of heat exposure until the end of the test. However, this value could not be compared with NM I, as the numerical computation set the temperature at the back of the subcutaneous tissue as a constant boundary condition.
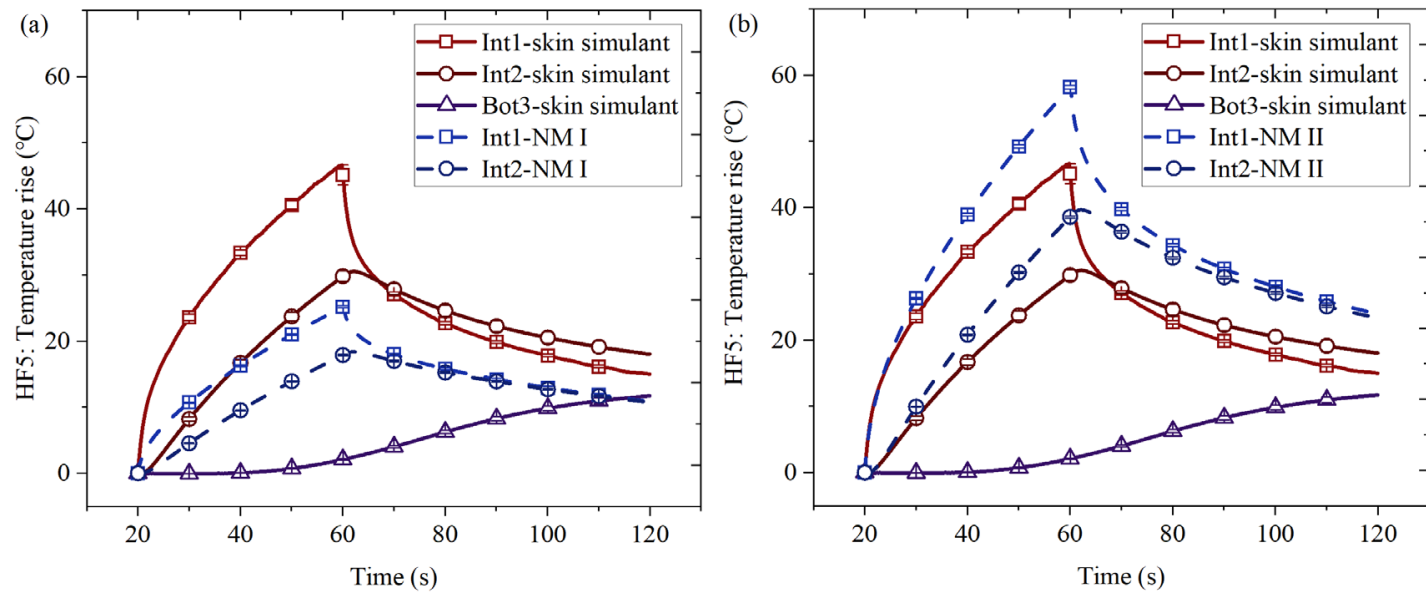

Fig. 3 Temperature rise of the skin simulant and the numerical models under radiant heat (example: $5 \mathrm{~kW} / \mathrm{m}^{2}$, HF5). (a)

Comparison with NM I;(b) Comparison with NM II.

\section{(2) Comparison of temperature variation rate}

It was confirmed that, overall, the skin simulant showed very similar behaviours compared to the temperature variation rate at Int 1 and Int2 as predicted by the numerical models (Fig. 4). This demonstrates that the development method of the skin simulant with water-filled sweating channels can feasibly simulate the heat transfer of human skin. However, differences in the absolute value of variation rate were still observed between the skin simulant and NM I, which explained the difference in temperature variation (Fig. 3a) in detail.

The results show that the temperature increase rate at Int 1 on the skin simulant was greater than that of NM I, especially at the initial phase of heat exposure (Fig. 4 (a1), the starting point: 10.6 (skin simulant), $\left.5.2(\mathrm{NMI}){ }^{\circ} \mathrm{C} / \mathrm{s} ; 20-40 \mathrm{~s}: 1.7,0.8^{\circ} \mathrm{C} / \mathrm{s} ; 40-60 \mathrm{~s}: 0.7,0.4{ }^{\circ} \mathrm{C} / \mathrm{s}\right)$. The temperature increase rate at Int 2 on the skin simulant was also greater than that of NM I (Fig. 5 (a2), 20-60 s: $0.7,0.4{ }^{\circ} \mathrm{C} / \mathrm{s}$ ). The numerical model analyses (Fig. S2) demonstrate that both lower thermal conductivity and lower volumetric heat capacity of the skin simulant may lead to the higher temperature variation rate at Int 1 on the skin simulant. However, for the temperature variation rate at Int2, the difference of the temperature variation rate between the skin simulant and NM I may be dominated by the volumetric heat capacity rather than the 
thermal conductivity. Besides, for the skin simulant at the beginning of the exposure, unlike the hightemperature increase rate at Int1, the temperature increase rate at Int2 was close to zero. The delayed increase at Int 2 was due to the deeper position of Int 2 in comparison to Int 1 and was consistent with the performance of NM I.

During the cooling phase, the average temperature decrease rates at Int 1 and Int2 on the skin simulant were also greater than that of NM I. And the difference between the skin simulant and NM I was greater at the beginning of the cooling phase than the later stage (Fig. 4 (a1), (a2), for Int1, the starting point: 9.2 (skin simulant), -5.0 (NMI) ${ }^{\circ} \mathrm{C} / \mathrm{s} ; 60-80 \mathrm{~s}:-1.1,-0.5^{\circ} \mathrm{C} / \mathrm{s} ; 80-120 \mathrm{~s}:-0.2,-0.1^{\circ} \mathrm{C} / \mathrm{s}$; for Int2, 60-80 s, $\left.-0.3,-0.1{ }^{\circ} \mathrm{C} / \mathrm{s} ; 80-120 \mathrm{~s},-0.2,-0.1{ }^{\circ} \mathrm{C} / \mathrm{s}\right)$. In contrast with the sudden temperature drop at Int1 at the beginning of cooling phase (maximum decrease rate: $9.2{ }^{\circ} \mathrm{C} / \mathrm{s}$ ), the temperature drop at Int2 was moderate (maximum decrease rate: $0.6{ }^{\circ} \mathrm{C} / \mathrm{s}$ ).
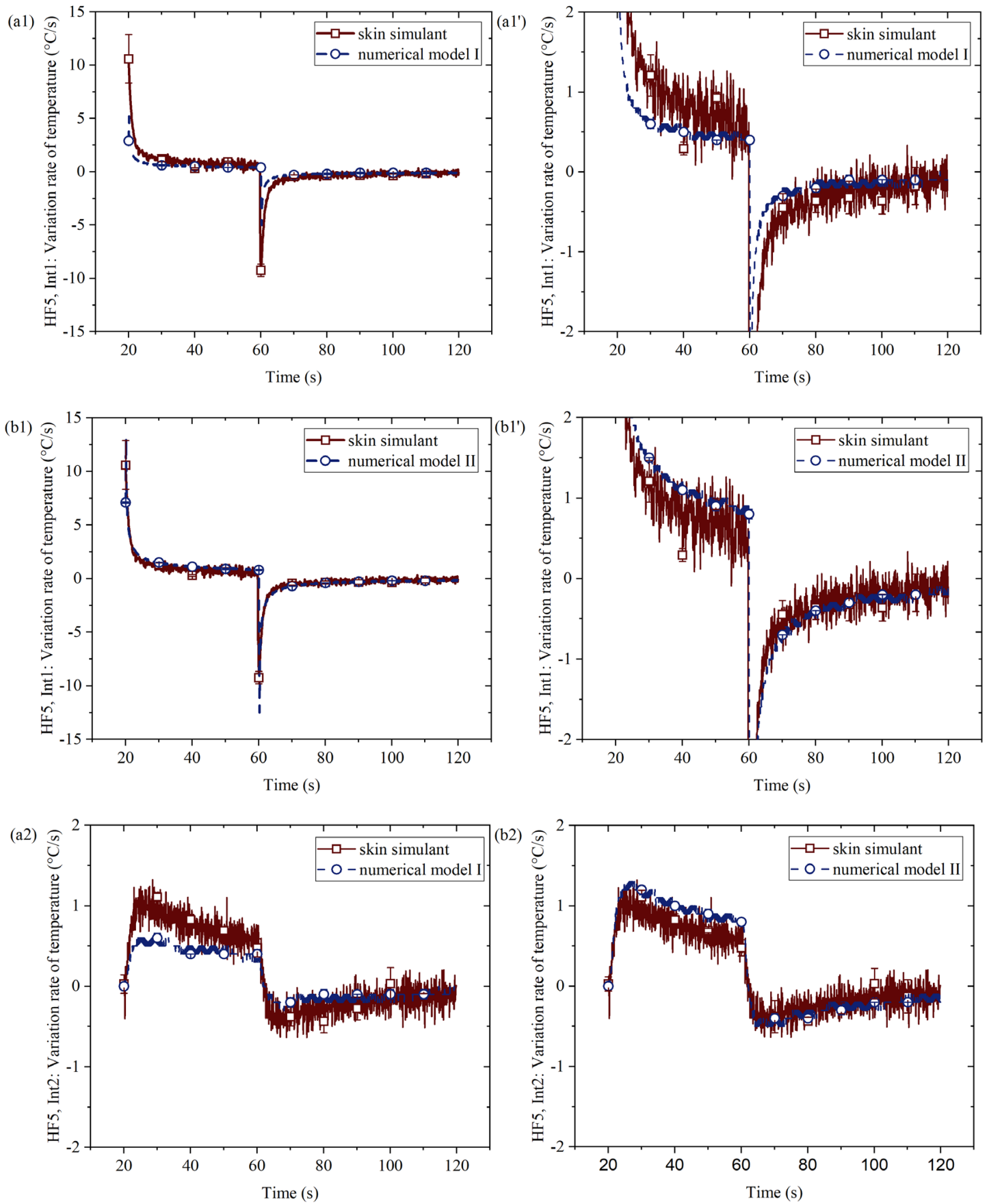
Fig. 4 Temperature variation rate of the skin simulant and numerical models under $5 \mathrm{~kW} / \mathrm{m}^{2}$ radiant heat. (a1) NM I, Int1, (a1') NM I, Int1, Y-axis: -2-2 ${ }^{\circ} \mathrm{C} / \mathrm{s}$, (a2) NM I, Int2; (b1) NM II, Int1, (b1') NM II, Int1, Y-axis: -2-2 ${ }^{\circ} \mathrm{C} / \mathrm{s}$, (b2) NM II, Int2.

\subsubsection{Comparison with NM II}

\section{(1) Comparison of temperature rise}

Under radiant heat HF5, at the beginning of the heat exposure, the temperature rises at Int1 and Int 2 on the skin simulant were close to the ones predicted by NM II (Fig. 3b, Int1, 20.0-23.0 s, RMSD: $0.36^{\circ} \mathrm{C}$; Int2, 20-21.5 s, RMSD: $0.01^{\circ} \mathrm{C}$ ). The results indicated that the large temperature difference between the skin simulant and NM I was mostly due to the different values of the thermal properties of skin layers adopted in the skin simulant and NM I. After $23.0 \mathrm{~s}$ and $21.5 \mathrm{~s}$, the temperature rises at Int 1 and Int 2 on the skin simulant started becoming lower than that of NM II (at the end of the heat exposure: $12.1,8.7^{\circ} \mathrm{C}$ ). For the skin simulant, the lower temperature at Int 1 and Int 2 and the higher temperature at Bot 3 could partly be due to the sweat channels, which are connected to the external pump system. This may facilitate heat dissipation from Int 1 and Int2 and heat transfer through the backside of the skin simulant.

\section{(2) Comparison of temperature variation rate}

Figures 5 (b1) and (b2) show that during the heat exposure, the increase rates at Int1 and Int2 on the skin simulant (Int1, 23-60 s: $0.9^{\circ} \mathrm{C} / \mathrm{s}$; Int2, 21.5-60 s: $0.8^{\circ} \mathrm{C} / \mathrm{s}$ ) were lower than those predicted by NM II (Int1, 23-60 s: $1.2^{\circ} \mathrm{C} / \mathrm{s}$; Int2, 21.5-60 s: $1.0^{\circ} \mathrm{C} / \mathrm{s}$ ). During the cooling phase, the temperature decrease rates at Int 1 and Int 2 on the skin simulant (Int1: $-0.5^{\circ} \mathrm{C} / \mathrm{s}$, Int2: $-0.2{ }^{\circ} \mathrm{C} / \mathrm{s}$ ) were also lower than those of NM II (Int1: $-0.6^{\circ} \mathrm{C} / \mathrm{s}$, Int $2:-0.3^{\circ} \mathrm{C} / \mathrm{s}$ ).

Table 3 presents the RMSD of the temperature variation rate between the skin simulant and NM I and NM II. It demonstrates that the RMSDs with NM II at all the radiant heat intensities were smaller than those with NM I. That is, compared to NM I, the variation rates at Int1 and Int 2 of NM II were closer to those of the skin simulant. This could be due to the same thermal properties being used in the skin simulant and NM II. As the property values used in NM I (i.e. ISO 13506-2) are representative of in vivo values for the forearms of test subjects [58] and there are large variations in skin properties at different body locations $[26,59,60]$, we accepted that there was a larger difference between the skin simulant and NM I.

Table 3 Root-mean-square deviation (RMSD) of temperature variation rates between the skin simulant and numerical

\begin{tabular}{|c|c|c|c|c|c|c|c|c|c|}
\hline \multirow{2}{*}{ Phase } & \multirow{2}{*}{ Position } & \multicolumn{2}{|c|}{ HF3 } & \multicolumn{2}{|c|}{ HF4 } & \multicolumn{2}{|c|}{ HF5 } & \multicolumn{2}{|c|}{ HF10 } \\
\hline & & NM I & NM II & NM I & NM II & NM I & NM II & NM I & NM II \\
\hline \multirow{2}{*}{ Heating phase (20-60 s) } & Int1 & 0.70 & 0.40 & 0.99 & 0.67 & 1.13 & 0.64 & 2.21 & 1.12 \\
\hline & Int2 & 0.22 & 0.14 & 0.25 & 0.20 & 0.34 & 0.27 & 0.58 & 0.50 \\
\hline \multirow{2}{*}{ Cooling phase (60-120 s) } & Int1 & 0.48 & 0.29 & 0.62 & 0.39 & 0.75 & 0.50 & 1.46 & 0.71 \\
\hline & Int2 & 0.14 & 0.13 & 0.13 & 0.09 & 0.17 & 0.16 & 0.23 & 0.19 \\
\hline
\end{tabular}

\subsection{Temperature behaviours with sweating}

Figure 5 shows the temperature rise at Int1 under sweat rates 0, 30, 90 and $150 \mu \mathrm{L} / \mathrm{min}$. Under radiant heat HF5 (Fig. 5a), after the sweat moisture reached the temperature measurement point ( $25 \mathrm{~s})$, the temperature at Int1 under higher sweat rates (average increase rate during 25-35 s for SR90, SR150: $0.97,1.00{ }^{\circ} \mathrm{C} / \mathrm{s}$ ) rose slightly faster than that under lower sweat rates (SR0, SR30: $0.90,0.89{ }^{\circ} \mathrm{C} / \mathrm{s}$ ). This led to a higher temperature at SR90 and SR150 compared to SR0 and SR30, with the maximum 
temperature difference being $1.04-1.47{ }^{\circ} \mathrm{C}$. This could be due to the positive role of wet conduction under higher sweat rates. Compared to the dry temperature rise (SR0, SR $30^{2}: 18.1-22.1^{\circ} \mathrm{C}$ ), the maximum temperature rise caused by wet conduction was $5-8 \%$, which is in line with previous studies $(<3-9 \%)$ [39-41]. After the faster temperature increase at SR90 and SR150, the temperature rise started to slow down. For SR90, from 40.9 to $46.5 \mathrm{~s}$, the rate of temperature change decreased from 0.52 to $0.38{ }^{\circ} \mathrm{C} / \mathrm{s}$. For SR150, from 35.5 to $38.9 \mathrm{~s}$, the rate of temperature change decreased from 0.60 to $0.46{ }^{\circ} \mathrm{C} / \mathrm{s}$. The reduction in temperature change rate at higher sweat rates could be because the heat capacity of water began to dominate the heat transfer process, slowing down the temperature increase. Figure 6a presents the temperature at Int2 for different sweat rates, which show a similar effect of sweat moisture as that at Int1. For the temperature at Bot3, generally, the sweating conditions affected this temperature (Fig. $6 \mathrm{~b}, \mathrm{p}>0.05$ ) but no specific effect of sweat rate was observed. The inferred effect of moisture at Int 1 and Int 2 in the current study agreed with previous studies with pre-wetted materials [27, 43]. The previous studies showed that when the amount of added moisture in materials is at a comparatively low level (15-20\% [42] and 30-40\% [43] of material weight), heat transfer towards the skin thermal sensor was faster than in dry material. This can be attributed to the large difference in thermal conductivity between the material and the water. If a higher amount of moisture is contained in the material, the heat transfer towards the skin thermal sensor became slower than the material with a lower amount of water. For example, compared to 15\% moisture amount in the protective material, 50\% moisture amount increased the burn time by $27 \%$. This can be attributed to the large difference in specific heat between the material and water.

Under higher radiant heat intensity HF10 (Fig. 5b), the temperature variations at different sweat rates showed a similar trend to that under radiant heat HF5 (Fig. 5a). At SR0 and SR30, the temperature kept increasing during the heat exposure phase (20-80 s). At SR 90 and SR150, a higher sweat rate could first facilitate the temperature increase and then slow down the temperature increase. However, the positive effect of water thermal conductivity at SR90 and SR 150 was not significant at HF 10 compared with that at HF5. This could be due to the higher radiant heat intensity which led to less water stored in the material, thus making the effect of thermal conductivity less significant.

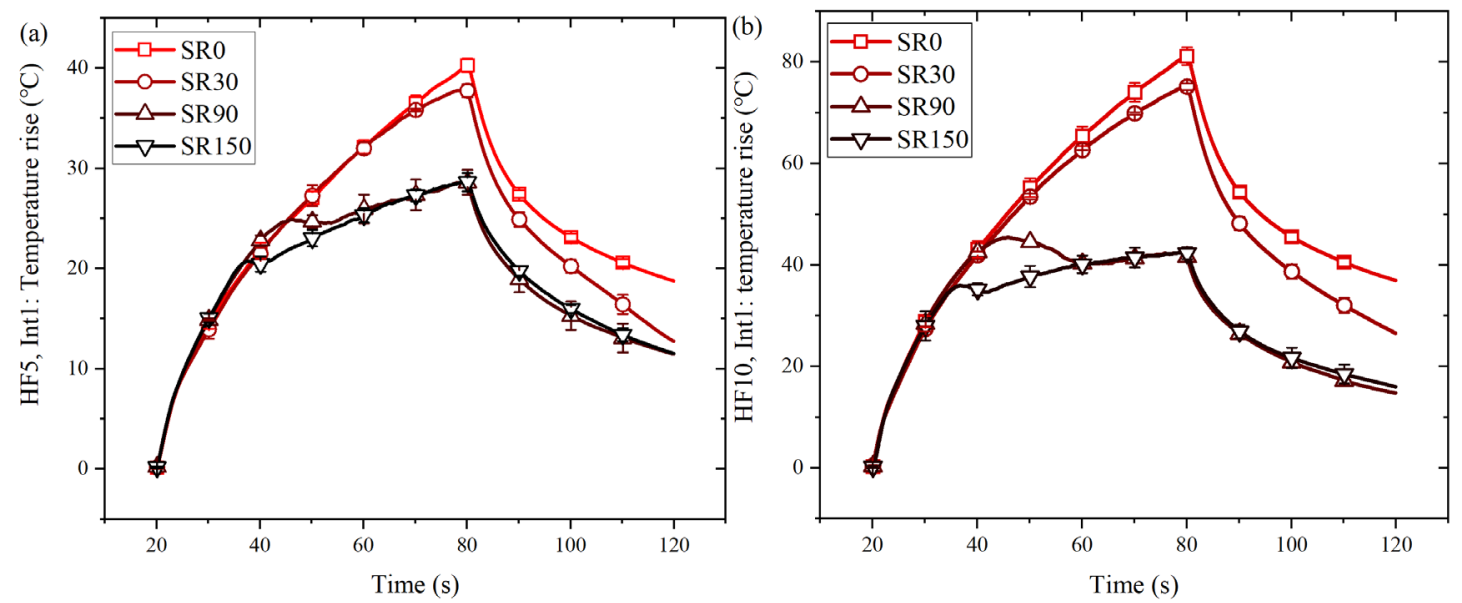

Fig. 5 Temperature rise at Int1 with clothing material under different sweat rates. (a) $5 \mathrm{~kW} / \mathrm{m}^{2}$ radiant heat. (b) 10 $\mathrm{kW} / \mathrm{m}^{2}$ radiant heat. SR0-150: sweat rate $0-150 \mu \mathrm{L} / \mathrm{min}$.

\footnotetext{
${ }^{2}$ For SR30, during the experiment, the sweat moisture did not reach the temperature measurement point due to the low sweat rate.
} 

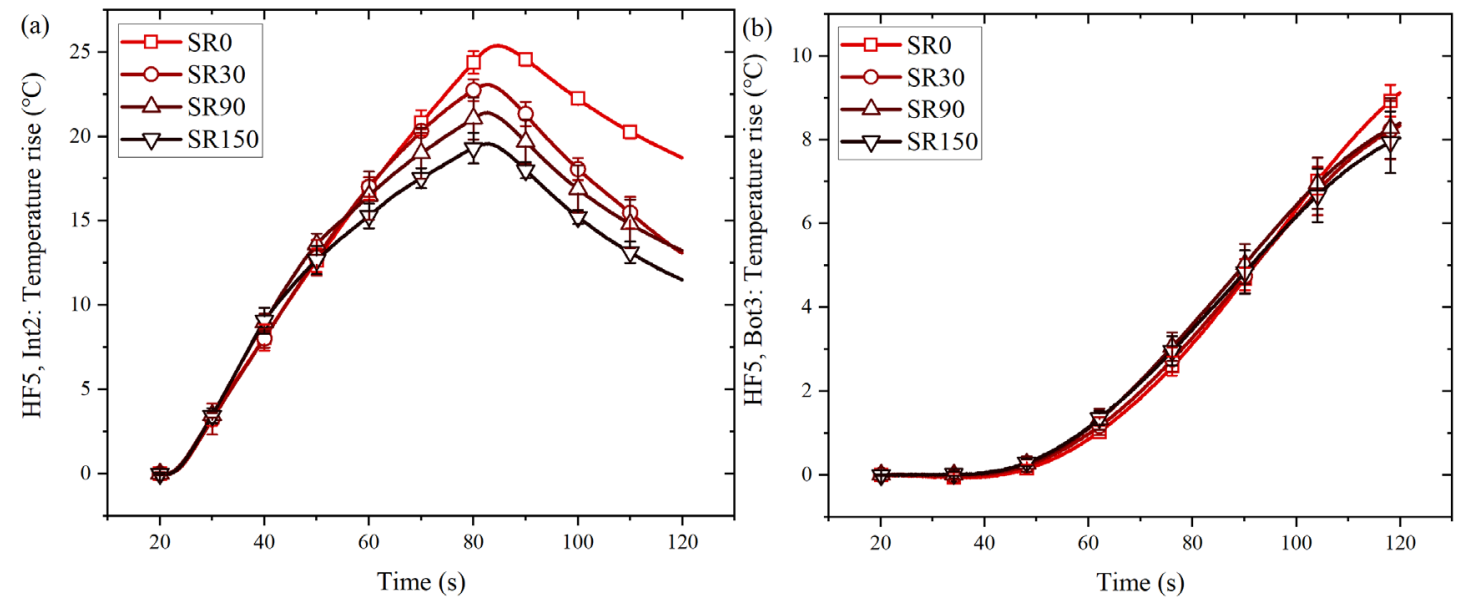

Fig. 6 Temperature rise at Int2 (a) and Bot3 (b) with clothing material under different sweat rates and $5 \mathrm{~kW} / \mathrm{m}^{2}$ radiant

heat. SR0-150: sweat rate $0-150 \mu \mathrm{L} / \mathrm{min}$.

\subsection{Measurement reproducibility}

Table 4 presented standard deviations (SD) and coefficients of variation (CV) for the measured temperature rise at the end of heat exposure for the four sweat rates.

For the nude skin simulant, the SDs and CVs of the temperature were in the $0.1-2.0^{\circ} \mathrm{C}$ range and lower than $10 \%$, respectively. For the clothed skin simulant, the temperature SDs and CVs were in the $0.01-$ $1.8^{\circ} \mathrm{C}$ range and lower than $10 \%$ respectively, except two values at Bot3 slightly higher than $10 \%$ (HF5/SR90: 10.6\%; HF5/SR150: 10.9\%). Overall, the results showed agreement with the previous study with dry skin simulant [26], which presented $0.1-1.9^{\circ} \mathrm{C}$ SD and $0.6-16.3^{\circ} \mathrm{C} \mathrm{CV}$. Based on the low SDs $\left(<2^{\circ} \mathrm{C}\right)$ and $\mathrm{CVs}(<10 \%)$ in the current study, the newly developed sweating skin simulant has good temperature measurement reproducibility under radiant heat with active sweating.

Table 4 Standard deviation and coefficient of variation of temperature in dry and sweating skin simulant states

\begin{tabular}{ccccccccccc}
\hline $\begin{array}{c}\text { State of skin } \\
\text { simulant }\end{array}$ & Heat flux & \multicolumn{2}{c}{ SR0 } & \multicolumn{2}{c}{ SR30 } & \multicolumn{2}{c}{ SR90 } & \multicolumn{2}{c}{ SR150 } \\
\hline Nude & HF5 & $0.5-2.2^{\circ}$ C & $3.9-6.9$ & $0.4-0.5$ & $0.9-5.8$ & $0.3-0.5$ & $1.7-4.3$ & $0.2-1.7$ & $3.8-7.2$ \\
Nude & HF10 & $0.3-2.0$ & $1.8-2.8$ & $0.1-1.7$ & $1.2-1.7$ & $0.5-4.2$ & $5.0-9.3$ & $0.3-4.4$ & $3.4-7.5$ \\
TPC & HF5 & $0.2-0.7$ & $1.7-7.8$ & $0.3-0.6^{* *}$ & $1.6-9.4$ & $0.4-1.2$ & $4.3-10.6$ & $0.4-0.9$ & $3.3-10.9$ \\
TPC & HF10 & $0.2-1.8$ & $2.2-3.7$ & $0.01-0.6$ & $0.1-0.8$ & $0.2-1.0$ & $2.3-3.1$ & $0.2-1.3$ & $3.0-3.4$ \\
\hline
\end{tabular}

*The range includes the value for Int1, Int2 and Int3. **For temperature at Int1 under HF5/SR30 of nude skin, only SD and CV of two repeated tests were present since the $3^{\text {rd }}$ test had to be discarded as the outlier, possibly because the water drop reached the sensor faster, which affected the measurement.

\section{Conclusions}

To understand the effect of active sweating on the heat transfer of clothed human skin under radiant heat exposure, we provided the first methodology to mimic the thermal properties of the different layers of human skin including controllable perspiration. Without sweating, the time courses for temperature showed the same trend for the skin simulant and the numerical model during the heating and cooling phases (RMSD 0.09-1.12). The effect of active sweating on heat transfer showed a similar moisture influence mechanism as previous research applying pre-wetted methodologies. At the beginning of active sweating (low amount of moisture in the clothing system), wet conduction was found to have a limited 
positive effect on heat transfer (5-8\%). With ongoing sweat release (increasing amount of moisture), heat capacity significantly reduced heat transfer and increased heat storage. The low standard deviations $\left(<2^{\circ} \mathrm{C}\right)$ and coefficients of variation $(<10 \%)$ proved the sweating skin simulant had high reproducibility for temperature measurement in dry and sweating conditions. Further applications of the sweating skin simulant in combination with the thermal torso and manikin can broaden their current research scope, finally contributing to the comprehensive evaluation of thermal protection and thermal physiology of the global clothed human body.

\section{Conflict of interest}

The authors declare that they have no conflict of interest.

\section{Acknowledgement}

The authors would like to thank DuPont, Switzerland for supplying the fabric for this study. The authors also appreciate the technical support from Jörg Gschwend, Peter Huber, Agnieszka K. Dąbrowska and Shelley Kemp. The authors would like to acknowledge the Fundamental Research Funds for the Central Universities (Grant NO. 2232018G-08), the financial support from the National Nature Science Foundation (Grant NO. 51576038), and Shanghai Municipal Natural Science Foundation (Grant NO. 17ZR1400500). The authors also acknowledge support from the China Scholarship Council.

\section{Reference}

1. Aliahmadipour, M., M. Abdolzadeh, and K. Lari, Air flow simulation of HVAC system in compartment of a passenger coach. Applied Thermal Engineering, 2017. 123: p. 973-990.

2. Singh, S. and H. Abbassi, 1D/3D transient HVAC thermal modeling of an off-highway machinery cabin using CFD-ANN hybrid method. Applied Thermal Engineering, 2018. 135: p. 406-417.

3. Haghighat, F., et al., Thermal Performance of Electrospun Core-Shell Phase Change Fibrous layers at Simulated Body Conditions. Applied Thermal Engineering, 2019: p. 113924.

4. Itani, M., et al., Significance of PCM arrangement in cooling vest for enhancing comfort at varied working periods and climates: Modeling and experimentation. Applied Thermal Engineering, 2018. 145: p. 772-790.

5. Bühler, M., et al., Heat protection by different phase change materials. Applied Thermal Engineering, 2013. 54(2): p. 359-364.

6. Fonseca, A., T. Mayor, and J. Campos, Guidelines for the specification of a PCM layer in firefighting protective clothing ensembles. Applied Thermal Engineering, 2018. 133: p. 81-96.

7. Song, G., et al., Thermal protective performance of protective clothing used for low radiant heat protection. Textile Research Journal, 2011. 81(3): p. 311-323.

8. Bogerd, N., et al., How to measure thermal effects of personal cooling systems: human, thermal manikin and human simulator study. 2010. 31(9): p. 1161.

9. Itani, M., et al., Significance of PCM arrangement in cooling vest for enhancing comfort at varied working periods and climates: Modeling and experimentation. 2018. 145: p. 772-790. 
10. Itani, M., et al., The effect of PCM placement on torso cooling vest for an active human in hot environment. 2016. 107: p. 29-42.

11. Shim, H., E. McCullough, and B.J.T.R.J. Jones, Using phase change materials in clothing. 2001. 71(6): p. 495-502.

12. Yoo, H., J. Lim, and E.J.T.R.J. Kim, Effects of the number and position of phase-change material-treated fabrics on the thermo-regulating properties of phase-change material garments. 2013. 83(7): p. 671-682.

13. Cheng, Y., J. Niu, and N. Gao, Thermal comfort models: A review and numerical investigation. Building and Environment, 2012. 47: p. 13-22.

14. Mandal, S. and G. Song, Thermal sensors for performance evaluation of protective clothing against heat and fire: a review. Textile Research Journal, 2015. 85(1): p. 101-112.

15. ISO 13506-2:2017 Protective clothing against heat and flame -- Part 2: Skin burn injury prediction -- Calculation requirements and test cases. 2017.

16. Kothari, V.K. and S. Chakraborty, Thermal protective performance of clothing exposed to radiant heat. Journal of The Textile Institute, 2015. 106(12): p. 1388-1393.

17. Mandal, S., et al., Characterization of textile fabrics under various thermal exposures. Textile Research Journal, 2012. 83(10): p. 1005-1019.

18. Stroup, D.W., R.A. McLane, and W.H. Twilley, Full ensemble and bench scale testing of fire fighter protective clothing. NISTIR, 2007. 7467: p. 1-75.

19. Zhu, F.-L., W.-Y. Zhang, and G.-W. Song, Heat transfer in a cylinder sheathed by flameresistant fabrics exposed to convective and radiant heat flux. Fire Safety Journal, 2008. 43(6): p. 401-409.

20. Sun, G., et al., Radiant Protective and Transport Properties of Fabrics Used by Wildland Firefighters. Textile Research Journal, 2016. 70(7): p. 567-573.

21. Mandal, S. and G. Song, An Empirical Analysis of Thermal Protective Performance of Fabrics Used in Protective Clothing. Annals of Occupational Hygiene, 2014. 58(8): p. 1065-1077.

22. ASTM F1930-18, Standard Test Method for Evaluation of Flame-Resistant Clothing for Protection Against Fire Simulations Using an Instrumented Manikin, ASTM International, West Conshohocken, PA, 2018, www.astm.org.

23. Pennes, H.H.J.J.o.a.p., Analysis of tissue and arterial blood temperatures in the resting human forearm. 1948. 1(2): p. 93-122.

24. Shen, W., J. Zhang, and F. Yang, Skin thermal injury prediction with strain energy. 2005, De Gruyter.

25. Fu, M., W. Weng, and H.J.N.H.T. Yuan, Part A: Applications, Numerical simulation of the effects of blood perfusion, water diffusion, and vaporization on the skin temperature and burn injuries. 2014. 65(12): p. 1187-1203.

26. Zhai, L., et al., Development of a multi-layered skin simulant for burn injury evaluation of protective fabrics exposed to low radiant heat. Fire and Materials, 2018: p. 1-9.

27. Barker, R.L., et al., Effects of Moisture on the Thermal Protective Performance of Firefighter Protective Clothing in Low-level Radiant Heat Exposures. Textile Research Journal, 2006. 76(1): p. 27-31.

28. Barker, R.L., A.S. Deaton, and K.A. Ross, Heat Transmission and Thermal Energy Storage in Firefighter Turnout Suit Materials. Fire Technology, 2010. 47(3): p. 549-563. 
29. Fu, M., W.-G. Weng, and H.-Y. Yuan, Quantitative investigation of air gaps entrapped in multilayer thermal protective clothing in low-level radiation at the moisture condition. Fire and Materials, 2016. 40(2): p. 179-189.

30. Fu, M., W.-G. Weng, and H.-Y. Yuan, Quantitative assessment of the relationship between radiant heat exposure and protective performance of multilayer thermal protective clothing during dry and wet conditions. J Hazard Mater, 2014. 276: p. 383-92.

31. Song, G.-W., W. Cao, and G. Farzan, Analyzing stored thermal energy and thermal protective performance of clothing. Textile Research Journal, 2011. 81(11): p. 1124-1138.

32. Keiser, C. and R.M. Rossi, Temperature Analysis for the Prediction of Steam Formation and Transfer in Multilayer Thermal Protective Clothing at Low Level Thermal Radiation. Textile Research Journal, 2008. 78(11): p. 1025-1035.

33. Lee, Y.M. and R.L. Barker, Effect of moisture on the thermal protective performance of heatresistant fabrics. Journal of Fire Sciences, 1986. 4(5): p. 315-331.

34. Lawson, L.K., et al., Moisture effects in heat transfer through clothing systems for wildland firefighters. International journal of occupational safety and ergonomics, 2004. 10(3): p. $227-$ 238.

35. Song, G.-W., et al., Thermal protective performance of protective clothing used for low radiant heat protection. Textile Research Journal, 2010. 81(3): p. 311-323.

36. Rossi, R.M. and T. Zimmerli, Influence of humidity on the radiant, convective and contact heat transmission through protective clothing materials, in Performance of Protective Clothing: Fifth Volume, J. Johnson and S. Mansdorf, Editors. 1996, ASTM International: West Conshohocken, PA. p. 269-280.

37. Stull, J.O., Comparative thermal insulative performance of reinforced knee areas of firefighter protective clothing, in Performance of Protective Clothing: Issues and Priorities for the 21 st Century: Seventh Volume. 2000, ASTM International. p. 312-328.

38. Mäkinen, H., Smolander, J., \& Vuorinen, H. , Simulation of the effect of moisture content in underwear and on the skin surface on steam burns of fire fighters, in Performance of Protective Clothing: Second Symposium. 1988, ASTM International. p. 415-421.

39. Chen, Y., J. Fan, and W. Zhang, Clothing thermal insulation during sweating. Textile Research Journal, 2003. 73(2): p. 152-157.

40. Bröde, P., et al., Non-evaporative effects of a wet mid layer on heat transfer through protective clothing. European journal of applied physiology, 2008. 104(2): p. 341-349.

41. Havenith, G., et al., Apparent latent heat of evaporation from clothing: attenuation and "heat pipe" effects. J Appl Physiol (1985), 2008. 104(1): p. 142-9.

42. Barker, R.L., et al., Effects of Moisture on the Thermal Protective Performance of Firefighter Protective Clothing in Low-level Radiant Heat Exposures. Textile Research Journal, 2016. 76(1): p. 27-31.

43. Mäkinen, H., J. Smolander, and H. Vuorinen, Simulation of the Effect of Moisture Content in Underwear and on the Skin Surface on Steam Burns of Fire Fighters. 1988: p. 415-415-7.

44. Guan, M., et al., Apparent evaporative cooling efficiency in clothing with continuous perspiration: A sweating manikin study. International Journal of Thermal Sciences, 2019. 137: p. $446-455$. 
45. Guan, M., et al., Effect of perspired moisture and material properties on evaporative cooling and thermal protection of the clothed human body exposed to radiant heat. Textile Research Journal. 0(0): p. 0040517518817067.

46. Fu, M., W.-G. Weng, and H.-Y. Yuan, Combined effects of moisture and radiation on thermal performance of protective clothing: experiments by a sweating manikin exposed to low level radiation. International Journal of Clothing Science and Technology, 2015. 27(6): p. 818-834.

47. MacRae, B.A., et al., Skin Temperature Measurement Using Contact Thermometry: A Systematic Review of Setup Variables and Their Effects on Measured Values. Frontiers in physiology, 2018. 9: p. 29.

48. Boylan, A., C. Martin, and G. Gardner, Infrared emissivity of burn wounds. Clinical Physics and Physiological Measurement, 1992. 13(2): p. 125.

49. Hardy, J.D. and C. Muschenheim, The radiation of heat from the human body. J Clin Invest, 1934. 13(5): p. 817-83.

50. Jacques, S.L., Optical properties of biological tissues: a review. Physics in Medicine \& Biology, 2013. 58(11): p. R37.

51. Steketee, J., Spectral emissivity of skin and pericardium. Physics in Medicine \& Biology, 1973. 18(5): p. 686.

52. Vimieiro-Gomes, A., et al., Comparison of sweat rate during graded exercise and the local rate induced by pilocarpine. Brazilian journal of medical and biological research, 2005. 38(7): p. 1133-1139.

53. ANSI/ASHRAE Standard 55-2017, Thermal Environmental Conditions for Human Occupancy. 2004, ANSI/ASHRAE Standard: Atlanta, GA.

54. ISO 6942:2002 Protective clothing -- Protection against heat and fire -- Method of test: Evaluation of materials and material assemblies when exposed to a source of radiant heat. 2002, International Organization for Standardization: Geneva, Switzerland.

55. ISO 3801:1977, Textiles -- Woven fabrics -- Determination of mass per unit length and mass per unit area. 1977, International Organization for Standardization: Geneva, Switzerland.

56. ISO 5084:1966, Textiles -- Determination of thickness of textiles and textile products. 1996, International Organization for Standardization: Geneva, Switzerland.

57. ISO 11092:2014, Textiles -- Physiological effects -- Measurement of thermal and water-vapour resistance under steady-state conditions (sweating guarded-hotplate test). 2014, International Organization for Standardization: Geneva, Switzerland.

58. Stoll, A.M. and L.C. Greene, Relationship between pain and tissue damage due to thermal radiation. Journal of applied physiology, 1959. 14(3): p. 373-382.

59. Cohen, M.L., Measurement of the thermal properties of human skin. A review. Journal of investigative dermatology, 1977. 69(3).

60. Johnson, N., et al., An archive of skin-layer thicknesses and properties and calculations of scald burns with comparisons to experimental observations. Journal of Thermal Science and Engineering Applications, 2011. 3(1): p. 011003. 